\title{
Human Immunodeficiency Virus Infection Occupational Post- Exposure Prophylaxis
}

\author{
Samuel A. Olowookere \\ PEPFAR APINPLUS Clinic, \\ University College Hospital, P.M.B. 5116, Ibadan, Oyo-State, Nigeria
}

\section{SUMMARY}

The risk of acquiring Human Immunodeficiency Virus (HIV) infection following occupational exposure to HIV-infected blood is low. It has been considered that there is no risk of HIV transmission where intact skin is exposed to HIVinfected blood. However, health care workers who are occupationally exposed to HIV infection must have immediate access to post-exposure prophylaxis (PEP). The risk of HIV transmission through the route of injury sustained must be assessed and adequate management given. Postexposure prophylaxis (PEP) should be commenced within 1-2 hours of exposure and should last one month for it to be effective. All health care workers who report exposure to HIV at work whether given PEP or not should be followed up for six months before a negative antibody test is used to reassure the individual that infection has not occurred. The objective of this article is to create awareness among health care workers, particularly resident doctors, who by the nature of their work are exposed to potentially infected body fluids so that they can present themselves rapidly for risk assessment and commencement of ART if necessary in the event of an occupational exposure to HIV.

\section{INTRODUCTION}

Human Immunodeficiency Virus (HIV) is the virus that causes Acquired Immune Deficiency Syndrome (AIDS). It can be transmitted from one person to another through exposure to blood or body fluids

All Correspondence to Dr S.A.Olowookere

PEPFAR APINPLUS Clinic

University College Hospital,

P.M.B. 5116, Ibadan,

Oyo-state, Nigeria.

E-mail: sanuolowookere@yahoo.com that contain the virus. Such fluids that contain the virus include blood, semen, vaginal fluid, human breast milk, amniotic fluid, cerebrospinal fluid, pericardial fluid, peritoneal fluid, pleural fluid, synovial fluid and exudative or other tissue fluid from burns or skin lesions [1]. Other body fluid like sweat, tears, saliva, urine and stool do not contain significant quantities of HIV unless there is blood mixed with them[1,2]. HIV is not transmitted through intact skin. The principal risks of acquiring HIV infection are through unprotected sexual contact, infant born to an HIV infected woman, breast feeding and percutaneous (through exposure of disrupted skin to an infected person's blood)[1].

In the work environment, health care workers may be occupationally exposed to HIV infection. Health care workers include all paid and unpaid persons working in health care settings who have the potential for exposure to infectious material, for example blood, tissue, and specific body tissues and medical supplies, equipment, or environ-mental surfaces contaminated with these substances. Health care workers include doctors, nurses, pharmacists, nursing assistants, emergency medical service personnel, therapists, students and trainees, technicians and persons not directly involved in patient care but potentially exposed to blood and body fluids (e. g laboratory scientists and technologists, clerical, housekeeping, maintenance and volunteer personnel). The same principle of postexposure management could be applied to other workers who have potential for occupational exposure to blood and body fluids in other settings. [1]

The risk of acquiring HIV infection following occupational exposure to HIV infected blood is low. Epidemiological studies have indicated that the average risk for HIV infection after percutaneous exposure to HIV infected blood in health care settings 
is about $0.3 \%$. After a mucocutaneous exposure the average risk is estimated at less than $0.1 \%$. It has been considered that there is no risk of HIV transmission where intact skin is exposed to HIVinfected blood [2]. Four factors are associated with increased risk of occupationally acquired HIV infection:

- Deep injury

- Visible blood on the device which caused the injury

- Injury with a needle which had been placed in a source patient's blood vessel

- Terminal HIV-related illness in the source patient.

It is estimated that the risk of HIV transmission after percutaneous exposure involving larger volumes of blood, particularly, if the source patient's viral load is high, exceeds the average risk of $0.3 \%[2,3]$.

It has been shown that immediate administration of antiretroviral drugs may prevent infection from occurring. Studies in health care workers who have had needle stick exposures have shown that post"- exposure treatment with antiretroviral drugs can reduce the risk by $79 \%$ [4].

\section{Risk Assessment and Management}

There are three types of exposure in health care settings associated with significant risk. These are:

- Percutaneous injury (from needles, instruments, bone fragments, significant bites which break the skin, and so on);

- Exposure of broken skin (abrasions, cuts, eczema and so on)

- Exposure of mucous membranes including the eye.

The Risk Is Assessed As Follows:

Negligible Risk: for example intact skin visibly contaminated with blood or body fluids; kissing, casual touching.

Management: reassurance and discharge

Low Risk: solid needle, superficial exposure on intact skin Small volume (drops of blood) on mucous membrane or non-intact skin exposures.Source is asymptomatic or viral load $<1500$ copies $/ \mathrm{ml}$

Management: counsel patient about risk of HIV, $\mathrm{HBV}$ and $\mathrm{HCV}$ transmission
Discuss risk of HIV post-exposure prophylaxis- if risk outweighs potential benefits, PEP not recommended.

Moderate Risk: for example skin-penetrating needle contaminated with blood or body fluid; wound causing bleeding and produced by sharp instrument visibly contaminated with blood.

Management: counsel patient about risk of HIV, $\mathrm{HBV}$ and HCV transmission

Discuss risk of HIV post-exposure prophylaxis. Accelerated HBV immunization or booster if already immunized. Give 2-drug combination if required.

High Risk: large bore needle, deep injury, and visible blood on device, needle in patient's artery/ vein. Source known to be HIV, HBV or HCV infected. Large volume (major blood splash on mucous membrane or non-intact skin exposures) Source patient is symptomatic, acute seroconversion, high viral load.

Management: counsel patient about risk of HIV, $\mathrm{HBV}$ and HCV transmission. Discuss risk of HIV post-exposure prophylaxis. Accelerated HBV immunization or booster if already immunized. Consider HBV Immunoglobulin if source is a highly infectious HBV carrier and patient is susceptible. PEP definitely indicated. Give 3-drug combination therapy. This regimen needs to be modified if index case is likely to harbour drug resistant virus $[3,8]$. Table 1 illustrates the schedule of investigations recommended following exposure.

\section{HIV Post-Exposure Antiretroviral Drug Therapy}

PEP should be commenced within 1-2 hours of exposure and should last one month for it to be effective. At least 6 months should elapse after cessation of PEP before a negative antibody test is used to reassure the individual that infection has not occurred. Following any occupational exposure to HIV, whether or not PEP was prescribed, health care worker should attend occupational health follow up for 6 months and be prepared to report symptom of concern at any time. $[3,10]$ 
TABLE 1: Recommended schedule of investigations

\begin{tabular}{|c|c|}
\hline Period & Recommended investigations \\
\hline baseline & $\begin{array}{l}\text { Full blood count } \\
\text { Liver function test } \\
\text { Renal function test } \\
\text { HIV screening } \\
\text { Pregnancy test if EFV is } \\
\text { considered }\end{array}$ \\
\hline Two weeks & $\begin{array}{l}\text { Full blood count } \\
\text { Liver function test } \\
\text { Renal function test }\end{array}$ \\
\hline Six weeks & HIV screening \\
\hline Three months & HIV screening \\
\hline
\end{tabular}

- Mucosal exposure of the mouth or eye by splashing fluids

- Intact skin exposed to a large volume of blood or potentially infectious secretions

- Broken skin exposed to a small volume of blood or secretions. [5]

\section{Recommended 2-drug combination:}

- Zidovudine (ZDV) 300mg twice daily +lamivudine (3TC) 150mg twice daily

- Stavudine d4T40mg twice daily +lamivudine (3TC) $150 \mathrm{mg}$ twice daily

- Stavudine (d4T) 40mg twice daily +didanosine (ddI) $400 \mathrm{mg}$ once daily

TABLE 2: Antiretroviral drugs for post- exposure prophylaxis

\begin{tabular}{|c|c|c|c|}
\hline drug & formulation & Side effects & $\begin{array}{l}\text { Intake } \\
\text { recommendation }\end{array}$ \\
\hline zidovudine & $\begin{array}{l}\text { Tab 300mg } \\
\text { Caps. } \\
\text { 100/250mg } \\
\text { susp.10mg/ml }\end{array}$ & $\begin{array}{l}\text { Neutropenia+/- } \\
\text { anaemia, nausea, } \\
\text { headache, hepatitis, } \\
\text { myopathy, nail } \\
\text { pigmentation. }\end{array}$ & $\begin{array}{l}\text { Can be given with } \\
\text { food; capsules can } \\
\text { be opened and } \\
\text { dissolve in water }\end{array}$ \\
\hline lamivudine & $\begin{array}{l}\text { Tab. 100/150mg; } \\
\text { Susp. 10mg/ml } \\
\text { (Room temp) }\end{array}$ & $\begin{array}{l}\text { Pancreatitis, peripheral } \\
\text { neuropathy, nausea, } \\
\text { diarrhea, cough, } \\
\text { headache, insomnia, } \\
\text { rash, alopecia, muscle } \\
\text { disorder }\end{array}$ & $\begin{array}{l}\text { Can be given with } \\
\text { food }\end{array}$ \\
\hline nelfinavir & or $625 \mathrm{mg}$ & $\begin{array}{l}\text { Diarrhea, nausea, } \\
\text { rash, exacerbation } \\
\text { of chronic liver } \\
\text { disease }\end{array}$ & $\begin{array}{l}\text { Best given with food } \\
\text { (light meal or snack). } \\
\text { Can be crushed and } \\
\text { administered as } \\
\text { powder, or dissolved } \\
\text { in water. }\end{array}$ \\
\hline
\end{tabular}

The following types of exposure to HIV infected materials should be considered for post-exposure prophylaxis:

- Needle-stick injury or injury with a sharp object that has been used on a HIV positive patient.

\section{Recommended 3- drug combination:}

Any of the 2-drug combination and Efavirenz $(\mathrm{EFV})$. Efavirenz is not given if pregnancy is suspected or patient is in reproductive age group.

Preferred combination is a 2-drug combination and EFV (600mg once daily) or Nelfinavir (NFV) 
$1250 \mathrm{mg}$ bd or lopinavir/retonavir (LPV/ RTV)(400mg/100mg twice daily)

The chosen regimen is continued for 28 days or until the result of HIV test for the patient and exposed health worker is known to be negative. $[5,9]$

\section{Care of Site Contaminated with Potentially} HIV-Infected Body Fluid

In the event of an injury with a sharp object such as a needle or scalpel that has been used on a patient or in the event of a mucous membrane surface contaminated with blood or secretions from a patient, the following steps should be followed:

- Allow blood to flow freely from wound if bleeding.

- Wash exposed area thoroughly with soap and water but without scrubbing.

- Rinse eye or mouth with plenty of water if contaminated.

- Report the injury immediately to a senior member of staff, supervisor or the post exposure prophylaxis designated officer of the unit.

- Take antiretroviral drugs recommended for post-exposure prophylaxis immediately- this should be started within one hour if possible and at the latest within 72 hours of the exposure. Persons presenting after 72 hours should also be considered for post-exposure prophylaxis.

- Ascertain the HIV status of the patient and the exposed health worker after providing appropriate pretest counseling- the standard rapid HIV antibody test that are currently used in the voluntary counseling and testing programme should be used and the result of the tests obtained as quickly as possible. $[5,6]$

\section{The Source Patient}

If initial assessment suggests a potential for HIV infection, consideration must be given to the HIV status of the source patient. This should be done with the source patient's consent. Adequate pretest counseling must be done by trained counselors. If the source patient is newly diagnosed HIV positive as a result of this process, he/she will need immediate access to specialist post-test counseling and assurance about confidentiality. Close support and clinical management will be needed on an ongoing basis. The source patient should also be informed promptly of HIV negative results with any post- test counseling appropriate to individual circumstances. [3]

\section{The Unknown Source}

If there is significant exposure and a source patient cannot be identified, risk assessment should be on individual basis. This will be informed by a consideration of the circumstances of the exposure, and the epidemiological likelihood of HIV in the source. In the vast majority of such exposures, it wound be difficult to justify the use of PEP. [3]

\section{Use of Antiretroviral Therapy Following} Exposure to Potentially Infectious Body Fluids Depending on the result of the HIV test, the following action should be taken:

If the source patient is HIV negative:

- No further post-exposure prophylaxis is required for the exposed health worker.

If the exposed health worker is HIV positive:

- No further post-exposure prophylaxis is necessary. The health worker should be referred for further counseling and management on a long term basis.

If the health worker is HIV negative and the source patient is HIV positive:

- Continue antiretroviral for a period of four weeks;

- Repeat health worker's HIV test at 3 months and 6 months after the initial test.

- Should the health worker seroconvert during this period then provide adequate care and counseling and refer for expert opinion and long term management

If it is not possible to determine the HIV status of the source patient:

- Assume that the source patient is positive and proceed according to guideline above $[5,6]$ 


\section{PEP: SPECIAL CIRCUMSTANCES}

\section{Viral drug resistance}

\section{Source patient}

Resistance should be suspected if there has been prolonged treatment with any antiretroviral agent, where there is clinical progression of disease or a persistently increasing viral load and or a decline in CD4 lymphocyte despite therapy, or a lack of virological response to a change in therapy. Antiretroviral drug resistance profiling where available should be taken into account when selecting PEP drugs. Specialist advice should be sought.

\section{Laboratory staff}

Similarly, in the case of laboratory based staff, knowledge about the source virus may be very important. This would be the case, particularly, if a virus with multiple nucleoside analogue resistance and or protease inhibitor resistance is being handled.

\section{Pregnancy}

Pregnancy does not preclude the use of PEP. Expert advice should always be sought if PEP is considered indicated for a female health care worker who is pregnant, after assessment of the circumstances of the exposure and of the source patient. Urgent pregnancy testing should be arranged for any female worker who cannot rule out the possibility of pregnancy, as part of the evaluation prior to the exposed worker reaching a personal, informed decision about starting PEP. A pregnant health care worker who has experienced an occupational HIV exposure should be counseled about the risk of HIV infection, about the risk of transmission to her baby, and about everything that is known and not known about the potential benefits and risks of antiretroviral therapy for her and her baby, to help her reach an informed personal decision about the use of PEP. $[3,10]$

\section{CONCLUSIONAND RECOMMENDATION}

Health care workers should observe universal precaution in the workplace so as to reduce to the barest minimum the possibility of injury. They should be informed and educated about the possible risks from occupational exposure and should be aware of the importance of seeking urgent advice following any needle stick injury or other occupational exposure. Regular training should ensure that everyone knows whom to report. Health workers who are occupationally exposed to HIV must have immediate access to PEP. The risk of HIV transmission through the route of injury sustained must be assessed and adequate management given. Post-exposure prophylaxis (PEP) should be commenced within an hour of exposure and should last four weeks to reduce risk of HIV seroconversion. All health workers who report exposure to HIV at work whether given PEP or not should be followed up for six months before a negative antibody test is used to reassure the individual that infection has not occurred.

\section{ACKNOWLEDGEMENTS}

I wish to acknowledge Professor Yetunde A. Aken'ova, Professor of Haematology and Principal Investigator PEPFAR APINPLUS UCH Ibadan and Professor Issac F. Adewole, former provost of the College of Medicine, University of Ibadan as well as the staff of PEPFAR APINPLUS Clinic Ibadan.

\section{REFERENCES}

1. Updated U.S. Public Health Services Guidelines for the Management of Occupational Exposure to HBV, HCV, and HIV and Recommendations for Postexposure Prophylaxis, MMWR, June 29 2001/50 (RR11); 1-42.

2. HIV Post- Exposure Prophylaxis. Guidance from the UK Chief Medical Officers' Expert Advisory Group on AIDS. Department of Health. February 2004. http:// www.advisorybodies.doh.gov.uk/eaga/ publications.html

3. Case-control study of HIV seroconversion in health care workers after percutaneous exposure to HIV-infected blood-France, United Kingdom, and United States, January 1988-August 1994. MMWR Morb Mortal Wkly Rep. 1995 Dec; 44(50):92933. Pubmed ID: 8531910.

4. Federal Ministry of Health. Guidelines for the Use of Antiretroviral drugs in Nigeria. Section 7; 56-58. 
5. CDC. Guidelines for Prevention of Transmission of Human Immunodeficiency Virus and Hepatitis B Virus to health care and public safety workers. MMWR June 13 1989. vol. 38, no. S-6. 6. HIV Prophylaxis following occupational exposure. Chapter in: criteria for the medical care of adults with HIV infection. AIDS Institute New York State Department of Health, 1993.

7. WHO. Guidance Modules on Antiretroviral Treatment. Module 7: Treatment following exposure to HIV. WHO/ASD/98.1.
8. WHO. HIV Post-Exposure Prophylaxis. http://www.who.int/hiv/topics/prophylaxis/en/ index1.html

9. Protocol for PostExposure Antiretroviral Prophylaxis: Occupational Health Services, YaleNew Haven Hospital. Updated October, 2002

10. CDC. Guidelines for prevention of transmission of human immunodeficiency virus and hepatitis B virus to health care and public safety workers. MMWR Morb Mortal Wkly Rep. 1989; 38(S6):3-37. 